\title{
Community safety under lockdown: early thoughts from isolation
}

\author{
Rob Mawby ${ }^{1}$ \\ Published online: 9 September 2020 \\ (c) Springer Nature Limited 2020
}

\section{Introduction}

The coronavirus pandemic has had a profound effect on mortality rates, on the health and care systems and on the economy. It has led to an increase in suicides (Kawohl and Nordt 2020). But has it also led to a reduction in crime? To put it bluntly: are we safer, from crime at least, since the pandemic took hold?

There has been a spate of research papers from sociologists, social and public policy specialists, educationalists and health care professionals, on the negative impact of COVID-19. However, of particular relevance to this journal is the relationship between the pandemic and crime. Personal movements have been constrained, particularly at the heart of the pandemic, due to either individual choice or government restrictions. This encouraged academics interested in situational influences on crime patterns to question the impact of changes in mobility on crime rates. For example, UCL (University College London) hosted an online symposium on Crime and COVID-19 on 16 July and has a webpage dedicated to the subject, ${ }^{1}$ and criminologists across the world have been assessing changes in crime rates and patterns of offending.

The theoretical basis for much of this analysis is derived from routine activity theory (Cohen and Felson 1979), rational choice theory (Cromwell et al. 1991) and crime pattern theory (Brantingham and Brantingham 1995). While varying in their emphases, essentially these focus on opportunities: offenders' decisions to target specific property or persons, based on their knowledge and awareness of the target, and the availability and accessibility of an appropriate target.

Three aspects of the situation that make a crime more or less likely-an available victim; a motivated offender; and a lack of protection or guardianship - have been significantly affected by the pandemic, in terms both of individuals' choices and government restrictions. Firstly, the availability of victims was in many respects

\footnotetext{
1 See: https://covid19-crime.com/.
}

Rob Mawby

professorrobmawby@hotmail.com

1 Harper Adams University, Newport, UK 
reduced. People were less likely to venture out in public, and since entertainment venues were closed, they were especially less likely to go out after dark. They were less likely to use public transport. This suggests that less victims would be available to steal from (e.g. pickpockets operate best in crowds, especially public transport), and public disorder offences linked to alcohol misuse would be lower. Secondly, potential offenders might have been less likely to go out, especially with co-offenders. Thirdly, there might have been more police around if other policing duties were reduced and if the police were actively enforcing the lockdown. Most importantly though is the question of self-guardianship and guardianship by passers-by or neighbours (Hollis-Peel and Welsh 2014; Reynald 2011). People spent more time at home which meant that their homes were better protected from burglars (who prefer empty houses), and they were better able to act as guardians of neighbours' property. On the other hand, there were less 'guardians' around in public places: less people in city centres meant less potential victims and offenders, but also less available witnesses/guardians. Moreover, the closure of many factories, shops and offices in city centres, shopping malls and industrial estates meant that these were potentially 'unguarded' 24/7. Consequently, while we might see a reduction in many offences, other might be more common. Whether this is a matter of displacement (Johnson et al. 2014), i.e. offenders continued to offend but changed their modus operandi, or whether these 'new' crimes were committed by different offenders, is a moot point.

\section{Crime patterns at the height of the pandemic}

In many, but not all, respects, researchers hypothesised a fall in crime. However, there are at least four problems with testing out these possibilities. Firstly, official statistics are dependent on victims reporting crimes and the police recording them, and in many cases, like domestic violence or Internet crime, they may not be reliable because a majority of crimes are not reported or recorded. In these circumstances, criminologists generally turn to victim survey data, but these are unavailable in the short term and in any case may be less useful for measuring changes in crime over short periods. Secondly, up-to-date criminal statistics may be inaccessible. This will vary according to the country and within countries, but there are some ongoing studies in the USA, Australia, Canada and the UK (see below). Thirdly, statistics are sometimes not detailed enough to allow us to identify subtle changes. For example, many police crime statistics fail to distinguish between domestic burglaries and break-ins to business premises, leading Felson, Jiang and Xu (2020) to compare burglaries by location (residential area or mixed use) rather than type. Finally, given that crime rates are subject to seasonal variation and may be subject to shifting patterns, it is necessary to include data covering ideally three or more years. Taking these limitations on board, researchers have found that some offences became less common, while a few increased.

Burglary is a useful example of changing patterns. Since homes were less likely to be empty at the height of the pandemic, we might expect residential burglaries to decline because burglars tend to target empty property. But burglars who operate when householders are at home, notably distraction burglars (Thornton et al. 2005), 
may be more active, using the emergency as an excuse to gain access. Furthermore, where shops, offices, schools, etc., were closed for longer periods, we might expect burglaries of businesses, storage facilities, schools and other public buildings to increase. These offences traditionally take place at night (Mawby 2001) but may have become more common in the daytime. Most of the research confirms this. Domestic burglary rates have been found to fall (Ashby 2020; Halford et al. 2020; Payne et al. 2020), although this did not seem to be the case in Los Angeles (Campedelli et al. 2020a). In contrast, commercial burglary rates have increased (Abrams 2020). Allied to this, Felson et al. (2020) found a shift from burglaries in residential areas to burglaries in mixed use areas of Detroit. In Vancouver, Hodgkinson and Andresen (2020) identified an initial rise in commercial burglaries that fell after police and business owners took counter-measures.

As suggested above, if less people are on the streets, robberies and thefts from the person may decrease. This is especially so for offences that require stealth, but lack of other pedestrians and traffic might mean that bag-snatching and robbery from the person by force would increase. Also, if people rely on more home deliveries, robbery from delivery vehicles might increase. Despite this, many studies report a decline in robberies (Campedelli et al. 2020a, b; Payne et al. 2020), albeit there appears as yet little refinement vis a vis different types of robbery or any differences between theft from the person and robbery.

With regard to other thefts, closure of many shops has resulted in a reduction in thefts from shops, a pattern found in various countries, including Australia (Payne et al. 2020), the UK (Halford et al. 2020) and the USA (Campedelli et al. 2020a). Less use of cars may mean a reduction in car-related crime, given that cars parked in urban centres are more vulnerable than those in garages, drives and residential streets (Clarke and Mayhew 1994), but thefts of bicycles may rise, and where social distancing means goods are delivered and left on doorsteps, thefts from doorsteps may increase. There is less evidence on these offences, although Payne et al. (2020) and Halford et al. (2020) found a decrease in thefts from cars.

In general, violence in public areas would be expected to fall, unless there are conflicts over shortages or social distancing around food shops, beaches, etc. Correspondingly, analysis of data for violent offences, especially in public places, suggests a decrease (Ashby 2020; Campedelli et al. 2020b; Payne et al. 2020), However, with more people confined at home, domestic violence would be expected to increase, involving not just women but also children and elderly parents. Strain theory supports this assumption (Agnew 1992). Looking further at the relationship between those involved, we might expect domestic violence against those in the same household to increase, but domestic violence against those from other households (for example, assaults by estranged or former partners) to decrease. The evidence for domestic violence is currently not detailed enough to take account of these distinctions. In Dallas, Piquero et al. (2020) noted a short-term rise in police reports but no long-term trend. Other, less systematic, evidence suggests that while there is no clear pattern for violence in private residences, at least according to police figures, calls to Women's Refuges and Helplines have risen dramatically, indicating that women attacked in their homes may feel trapped and unwilling to involve the police but more likely to seek alternative solutions (BBC News 2020a; Bradbury-Jones 
and Isham 2020; Graham-Harrison et al. 2020; Townsend 2020; Usher et al. 2020; WHO 2020).

While domestic violence is one offence that we might have anticipated would be intensified during the lockdown, another rather different example is Internet-based crime. With people confined at home, dependence on the Internet has increased. Correspondingly, frauds through phone and Internet would be expected to increase. These may be directly related to the pandemic (e.g. scams over selling face masks or COVID-19 testing kits), indirectly related to the pandemic (e.g. where customers are more dependent on purchasing goods online and are conned, where criminals offer government grants and loans, or where conmen prey on lonely women), or unrelated, as in the case of the plethora of money laundering scams that invite the reader to aid in the transfer of funds established by various former Asian or African leaders. Additionally, with schools closed and many working from home, children have been more likely to use the Internet unsupervised, putting them more at danger of grooming. While there has been far less research on online offending, UK and European sources also suggest an increase in online child abuse (BBC News 2020b; EUROPOL 2020). Additionally, impressionistic evidence from across the world also suggests a rise in Internet fraud and fraud linked to false claims by shadow businesses applying for government grants (Barth 2020; Campbell 2020; Lynch 2020; Tett 2020). One piece of research in the UK, by Buil-Gil et al. (2020), seems to confirm this. While only covering a 12-month period from May 2019-May 2020, and based on data from the website of Action Fraud, the UK National Fraud and Cybercrime Reporting Centre, they found a significant increase in various manifestations of cybercrime, including fraud associated with online shopping.

That said, the indications are that in general crime rates fell during the lockdown. However, this did not apply to all offence types nor indeed to all areas. Studies in the UK (Farrell 2020), Australia (Payne et al. 2020) and the USA (Abrams 2020; Campedelli et al. 2020b) demonstrate marked variations by area. There is some suggestion here that lower crime, higher status areas might have seen a more marked decrease (Campedelli et al. 2020b), possibly indicating that offenders, who traditionally travel short distances to commit their crimes (Wiles and Costello 2000), have become even more reluctant to travel. In Lancashire, however, Farrell (2020) notes an increase in ASB offences in rural areas, which may indicate both an increase in fly-tipping when legal refuse sites were closed and problems caused by visitors/day trippers. My ongoing research in tourist hotspots also suggests that under the strictest lockdown measures, crime fell in contrast to nearby nontourist areas.

\section{Tiptoeing out of lockdown}

Of course, there may have been a further increase in offending where people have been charged with breaking the laws restricting and controlling behaviour during the lockdown. Again there are variations between countries, both in the nature of the restrictions-travelling long distances, wearing facemasks, social distancing, etc.-and also on whether these restrictions are advisory or mandatory. However, as we tiptoe out of lockdown, the potential for interpersonal conflicts has increased. 
In England, partial easing of the lockdown was met by hoards of day and overnight visitors to rural areas like the Lake District and coastal areas like Devon and Cornwall, provoking a hostile reaction from local people who felt that population movement was increasing the risk of transmission from high-to-low rate regions (Gold 2020; Smallcombe 2020). This subsequently led to targeted vandalism of cars and second homes and in some cases violence. Antisocial behaviour and public disorder have also increased in tourist areas and areas catering for the NTE. We have also seen altercations over social distancing, wearing facemasks, etc., involving attacks on the transgressors or attacks by the transgressors on those attempting to enforce new regulations (Ng 2020; Simcox 2020; Robinson 2020; Willsher 2020). There is certainly the potential for intergenerational conflict or escalating hate crime.

But what about the longer-term implications of the pandemic? On one level, increased unemployment and poverty might mean that the social impacts of the pandemic outweigh situational shifts. Whether crime rates return to the pre-pandemic levels, however, also depends on situational factors, and the extent to which crime was reduced or displaced. Thus, during the pandemic:

- Some would-be offenders found the opportunity to commit their crime-of-choice restricted and so did not offend.

- Some would-be offenders found the opportunity to commit their crime-of-choice restricted, so offended in different ways, i.e. there was crime displacement.

- Some people who would not otherwise have offended took advantage of the new opportunities available during the lockdown and committed crimes they would not otherwise have committed.

The first perspective assumes that offenders are relatively specialised in their criminal behaviour. This is less likely among younger offenders and will vary according to offence type. The second perspective assumes that offenders are relatively flexible in their choice of crime. It is limited by offenders' limited skill sets. The third perspective assumes that there is a pool of potential criminals who are deterred from offending under normal conditions but due to temptation, financial hardship, stress, etc. (all of which may be more evident at this time) offend when circumstances change.

While the first perspective is true of some offenders, clearly perspectives 2 and 3 also applied during the pandemic. This change in offending patterns could, arguably, apply on at least five levels, or SPOTT.

- Spatial context For example, crimes in real space were reduced, but crimes in virtual space (i.e. online or phonecalls) increased. Since these require different skill sets, the increases were generally by different offenders.

- Physical location For example, violence committed in the home rather than in public places, in some cases by the same offenders but against mainly different victims, and a shift towards even more locally based crime, as the lockdown restricted travelling distances.

- Offence type For example, household burglary was reduced and corporate burglary increased, probably due to displacement. 
- Technique For example, burglary: if homes were more likely to be occupied, access might be gained by subterfuge rather than forced entry. Since such 'distraction burglaries' are often carried out by specialists and are unlike other burglaries, any increases would generally be by different offenders.

- Target As noted above, this includes a shift from household burglary to break-ins to offices, shops, etc. Additionally, in holiday resorts where there were less tourists, there may be a shift towards breaking into unoccupied holiday accommodation, especially second homes.

How, then will crime readjust after the pandemic: will there be a 'new normal' for crime too? That is:

- Will those would-be offenders who found the opportunity to commit their crimeof-choice restricted and so did not offend resume their pre-lockdown behaviour or not?

- Will those would-be offenders who found the opportunity to commit their crimeof-choice restricted and responded by offending in different ways return to old habits, continue with the new or become more flexible in their offending patterns?

- Will those who would not otherwise have offended but took advantage of the new opportunities available during the lockdown continue to offend?

While COVID-19 has inspired a plethora of quantitative research into changing crime patterns, post-COVID is set to inspire further research, incorporating a more detailed and qualitative review of offenders' career choices.

\section{References}

Abrams, D.S. 2020. COVID and crime: An early empirical look. In Paper to UCL Crime and COVID-19 Online Symposium, 16 July.

Agnew, R. 1992. Foundation for a general strain theory of crime and delinquency. Criminology 30 (1): 47-87.

Ashby, M. 2020. Initial evidence on the relationship between coronavirus and crime in the United States, Crime Science, 9.1, open access journal at https://link.springer.com/content/pdf/10.1186\%2Fs40 163-020-00117-6.pdf. Accessed 10 Aug 2020.

Barth, B. 2020. '5 ways COVID-19 is reshaping the cyber-crime economy, SC Media, 2 May. www. scmagazineuk.com/5-ways-covid-19-reshaping-cyber-crime-economy/article/1682098. Accessed 17 July 2020.

BBC News. 2020a. Coronavirus: Domestic Abuse Calls up 25\% Since Lockdown, Charity Says. www. bbc.co.uk/news/av/world-53014211/coronavirus-domestic-violence-increases-globally-during-lockd own. Accessed 17 July 2020.

BBC News. 2020b. Coronavirus: Increased risk of online child sexual abuse, BBC, 8 June. www.bbc. co.uk/news/uk-northern-ireland-52962266. Accessed 17 July 2020.

Bradbury-Jones, C., and L. Isham. 2020. The pandemic paradox: The consequences of COVID-19 on domestic violence. Journal of Clinical Nursing 29: 247-249.

Brantingham, P., and P. Brantingham. 1995. Criminality of place: Crime generators and crime attractors. European Journal on Criminal Policy and Research 3 (3): 5-26. 
Buil-Gil, D., F. Miró-Llinares, A. Moneva, S. Kemp, and N. Díaz-Castaño. 2020. Cybercrime and shifts in opportunities during COVID-19: A preliminary analysis in the UK. European Societies 22: 5. forthcoming.

Campbell, D. 2020. Blitz spirit? It's another bonanza for spivs and thieves, Guardian, 28 March. https ://www.theguardian.com/world/2020/mar/28/blitz-spirit-its-another-bonanza-for-spivs-and-thieves. Accessed 17 July 2020.

Campedelli, G.M., Favarin, S., and Aziani, A. 2020a. Exploring the effects and theoretical implications of SARS-CoV-2 containment policies: An empirical analysis of crime in Los Angeles. In Paper to UCL Crime and COVID-19 Online Symposium, 16 July.

Campedelli, G.M., Favarin, S., Aziani, A., and Piquero, A.R. 2020b. Disentangling community-level changes in crime trends during the COVID-19 pandemic in Chicago. In Paper to UCL Crime and COVID-19 Online Symposium, 16 July.

Clarke, R.V., and P. Mayhew. 1994. Parking patterns and car theft risks: Policy relevant findings from the British Crime Survey. Crime Prevention Studies 3: 91-107.

Cohen, L.E., and M. Felson. 1979. Social change and crime rate trends: A routine activity approach. American Sociological Review 44: 588-608.

Cromwell, P.F., J.N. Olson, and D.A.W. Avary. 1991. Breaking and Entering. Newbury Park, California: Sage.

EUROPOL. 2020. Exploiting isolation: offenders and victims of online child sexual abuse during the COVID-19 pandemic. www.europol.europa.eu/publications-documents/exploiting-isolation-offen ders-and-victims-of-online-child-s-during-covid-19-pandemic. Accessed 17 July 2020.

Farrell, G. 2020. Crime and mobility during the COVID-19 pandemic. In Paper to UCL Crime and COVID-19 Online Symposium, 16 July.

Felson, M., Jiang, S., and Xu, Y. 2020. Routine activity effects of the Covid-19 pandemic on burglary in Detroit, March, 2020, Crime Science, 9.1, open access journal at https://link.springer.com/content/ pdf/10.1186/s40163-020-00120-x.pdf. Accessed 10 Aug 2020.

Gold, T. 2020. The Cornish revolt against second-home owners, Spectator, 28 March. https://www.spect ator.co.uk/article/the-cornish-revolt-against-second-home-owners. Accessed 17 July 2020.

Graham-Harrison, E., Giuffrida, A. Smith, E., and Ford, L. 2020. Lockdowns around the world bring rise in domestic violence, Guardian, 28 March. www.theguardian.com/society/2020/mar/28/lockdownsworld-rise-domestic-violence?CMP=Share_iOSApp_Other. Accessed 17 July 2020.

Halford, E., Dixon, A., Farrell, G., Malleson, N., and Tilley, N. 2020. Crime and coronavirus: Social distancing, lockdown, and the mobility elasticity of crime, Crime Science, 9.1, open access journal at https://link.springer.com/content/pdf/10.1186/s40163-020-00121-w.pdf. Accessed 10 Aug 2020.

Hodgkinson, T., and M.A. Andresen. 2020. Show me a man or a woman alone and I'll show you a saint: Changes in the frequency of criminal incidents during the COVID-19 pandemic. Journal of Criminal Justice 69: 101706.

Hollis-Peel, M.E., and B.C. Welsh. 2014. What makes a guardian capable? A test of guardianship in action. Security Journal 27: 320-337.

Johnson, S.D., R.T. Guerette, and K. Bowers. 2014. Crime displacement: What we know, what we don't know, and what it means for crime reduction. Journal of Experimental Criminology 10: 549-657.

Kawohl, W., and C. Nordt. 2020. COVID-19, unemployment, and suicide. The Lancet Psychiatry 7 (5): 389-390.

Lynch, P. 2020. Criminals prey on coronavirus fears to steal $£ 2$ m, BBC News, 16 April. www.bbc.co.uk/ news/uk-england-52310804. Accessed 17 July 2020.

Mawby, R.I. 2001. Burglary. Cullompton: Willan Publishing.

Ng, K. 2020. Coronavirus: Video of drunk and disorderly British tourists flouting restrictions in Magaluf sparks anger, Independent, 16 July. https://www.independent.co.uk/news/world/europe/coronaviru s-magaluf-british-tourists-lockdown-restrictions-video-a9617726.html. Accessed 20 July 2020.

Payne, J.L., Morgan, A., and Piquero, A.R. 2020. A comparison of recorded offence rates and dynamic forecasts (ARIMA) in Queensland, Australia. In Paper to UCL Crime and COVID-19 Online Symposium, 16 July.

Piquero, A., Riddell, J., Bishopp, S., Narvey, C., Reid, J., and Piquero, N. 2020. Staying home staying safe? A short-term analysis of COVID-19 on Dallas domestic violence. In Paper to UCL Crime and COVID-19 Online Symposium, 16 July.

Reynald, D.M. 2011. Guarding Against Crime: Measuring Guardianship within Routine Activity Theory. London: Ashgate Publishers. 
Robinson, J. 2020. Shocking moment fist fight breaks out on packed London train 'over passenger not wearing a face mask, MailOnline, 11 August. https://www.dailymail.co.uk/news/article-86159 41/Shocking-moment-fist-fight-breaks-packed-London-train-face-mask.html?ito=push-notificati on\&ci=27600\&si=7200467. Accessed 12 Aug 2020.

Simcox, M. 2020. Fight breaks out on plane to Ibiza after two 'drunken and unruly English passengers' refused to wear face masks on KLM flight from Amsterdam, MailOnline, 2 August. www.dailymail. co.uk/news/article-8585439/Fight-breaks-KLM-plane-Ibiza-two-passengers-refused-wear-facemasks.html?ito=push-notification\&ci=26165\&si=7200467. Accessed 7 Aug 2020.

Smallcombe, M. 2020. Police's warning to angry second home vigilantes in Devon, Devon Live, 16 April. www.devonlive.com/news/devon-news/polices-warning-angry-second-home-4051288. Accessed 17 July 2020.

Tett, G. 2020. Why Covid-19 is a gift for cyber criminals, Financial Times, 15 July. www.ft.com/conte nt/935a9004-0aa5-47a2-897a-2fe173116cc9. Accessed 17 July 2020.

Thornton, A., C. Hatton, L. Ralph, and T. Owen. 2005. Understanding the older person's awareness and experience of doorstep crime: Results of a national survey. Crime Prevention and Community Safety: An International Journal 7 (1): 31-42.

Townsend, M. 2020. Revealed: Surge in domestic violence during Covid-19 crisis, Observer, 12 April. www.theguardian.com/society/2020/apr/12/domestic-violence-surges-seven-hundred-per-cent-ukcoronavirus. Accessed 17 July 2020.

Usher, K., N. Bhullar, J. Durkin, N. Gyamfi, and D. Jackson. 2020. Family violence and COVID-19: Increased vulnerability and reduced options for support. International Journal of Mental Health Nursing 29: 549-552.

WHO. 2020. Addressing violence against children, women and older people during the COVID-19 pandemic: Key actions, 17 June. https://apps.who.int/iris/bitstream/handle/10665/332458/WHO-2019nCoV-Violence_actions-2020.1-eng.pdf. Accessed 17 July 2020.

Wiles, P., and Costello, A. 2000. The 'road to nowhere': The evidence for travelling criminals. London: Home Office (HO Research Study no. 207).

Willsher, K. 2020. Man attacked in Paris launderette for asking customer to wear mask, Guardian, 4 August. www.theguardian.com/world/2020/aug/04/man-attacked-in-paris-launderette-for-askin g-customer-to-wear-mask. Accessed 7 Aug 2020.

Publisher's Note Springer Nature remains neutral with regard to jurisdictional claims in published maps and institutional affiliations. 